\title{
Retrograde long bone intramedullary pinning in wing fractures of the common buzzard (Buteo buteo)
}

\author{
IOSIF VASIU, CIPRIAN OBER, COSMIN MUREŞAN, RADU LĂCĂTUŞ*, \\ LIVIU OANA, ROMAN DĄBROWSKI**, COSMIN PEŞTEAN
}

\begin{abstract}
Department of Surgery, *Department of Semiology and Imagistics, University of Agricultural Science and Veterinary Medicine, Calea Mănăştur 3-5, 400372 Cluj-Napoca, Romania **Department and Clinic of Animal Reproduction, University of Life Sciences, Głęboka 30, 20-612 Lublin, Poland
\end{abstract}

Vasiu I., Ober C., Mureşan C., Lăcătuş R., Oana L., Dąbrowski R., Peştean C. Retrograde long bone intramedullary pinning in wing fractures of the common buzzard (Buteo buteo)

\section{Summary}

Three common buzzards (Buteo buteo) were brought to the veterinary emergency hospital in Cluj-Napoca with right wing trauma, inflicted by a car accident and multiple gunshot wounds. Clinical and Rtg examination were used to diagnose one humeral and two radio-ulnar fractures in the right wing. The fractures were reduced by using the simple intramedullary retrograde pinning technique, adapted to the requirements of the pneumatic avian bones. Radiological tests were performed at 3, 7 and 21 days postoperatively. The $X$-rays showed callus formation and healing processes. However, because of complications (paresis, muscular atrophy and osteomyelitis), the flight capacity could not be restored in all 3 cases. This is the first case series of right wing fractures, caused by gunshot and car accident trauma, to be reported in Romania. The orthopedic technique used had proved its effectiveness in healing long bone fractures, but due to presence of osteomyelitis, excessive fracture mobility and the sectioning of the radial nerve, the main objective, i.e. regaining flight capacity, was reached in only one patient.

Keywords: humeral, radio-ulnar, fracture, callus

The common buzzard (Buteo buteo) is a medium sized territorial bird of prey which measures between $51-57 \mathrm{~cm}$ in length and has a wing span of about 113$-128 \mathrm{~cm}$ with a round head, dark beak and yellow cere, with yellow feet and claws. The eyes are brownish yellow to grey but change quickly and the beak is hooked from the base. The plumage is variable with a short and wide tail. In general, adult subjects are darker with white underparts, and with brown stripes turning to reddish-brown on the abdomen. Females tend to get larger than males. It feasts mainly on birds, which constitutes 42 to $75 \%$ of the biomass eaten by these raptors, followed by small mammals, snakes, batrachians, insects and sometimes even with cereals, but it can also be a scavenger $(1,8,10,13)$.

It is located throughout Eurasia, including Romania, northern Africa and the Middle East. It is sedentary in Eastern Europe and during the cold seasons the local population increases due to migrations from the northern part of Eurasia $(10,18)$. Buzzards inhabit mountains, forests, marshlands, meadows and agricultural zones and often nest in plowed lands $(8,13,18)$.

The breeding season begins from the end of March and lasts until the end of April. They nest betweeen 1-4 eggs, with an average of 2.4 per season. On average, 1.9 young hatch and 1.3 juveniles fledge per breeding pair (8).

The fact that they are easily spotted during winter on roadside telegraph poles and forest canopy (10) makes them easy targets, predisposing them to gunshot wounds and even road killed victims.

In the common buzzard, the most common fracture cases $(41 \%)$ are forearm fractures, with a $92.1 \%$ occurrence in the hunting season, in which patients with comminuted lesions have the highest mortality rate $(75 \%)(2)$.

Some authors suggest (3) that in $50 \%$ of forearm fractures just 1 of the 2 bones are fractured, thus implying that surgical intervention is not mandatory because healing processes are sustained by the intact bone (3). Bone grafts may also be used when substantially bone tissue is lost (9). However, for birds intended to be released back into the wild, the surgical approach is the correct one in healing avian fractures (7).

In order to improve blood supply to the damaged tissues, and to accelerate the healing processes, active and passive physiotherapy techniques should be started as soon as possible. Initial physiotherapy 
includes normal activities of the animals such as food prehension and cage perch usage, followed by adopting techniques that improve and maintain cardiac resistance, joint mobility, flexibility and muscular tonus, according to each animal's needs (12)

\section{Case report}

The aim of this report is to present 3 cases of right wing fractures in the 3 juvenile common buzzards that were admitted at the veterinary emergency hospital in Cluj-Napoca (Tab. 1).

Case 1. The $1^{\text {st }}$ buzzard presented to the hospital had a right wing fracture caused by a car accident. After initial consultation, the bird was diagnosed with a closed distal humeral right wing fracture. The hawk was hospitalized and X-rays (Fig. 1) were obtained in order to confirm and acquire additional data regarding the affected wing. After careful analysis of the obtained data, the buz-

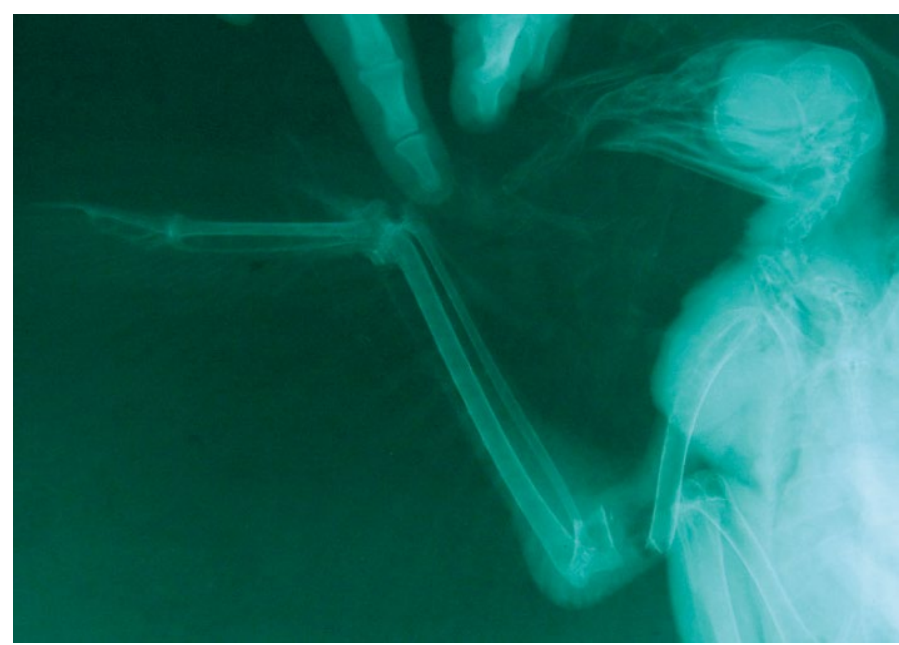

Fig. 1. Right wing X-ray of a closed, simple, humeral fracture with two bone fragments

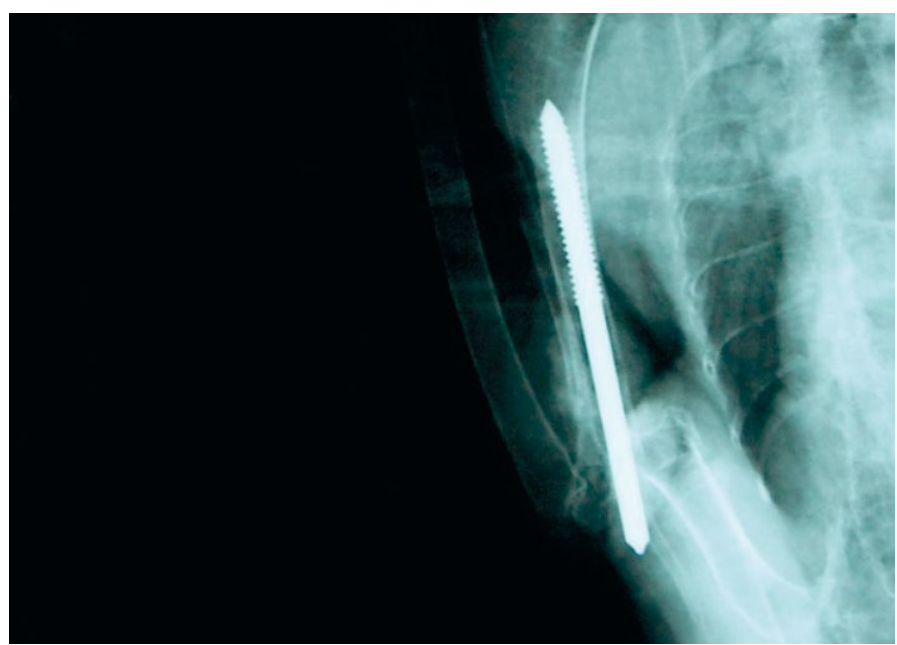

Fig. 2. X-ray exposure at 3 days after the intramedullary pinning of the humerus, showing healing activity and callus genesis zard was prepared for surgical intervention at the surgery department.

The pre-op anesthetic management (4) consisted of premedication with midazolam ( $4 \mathrm{mg} / \mathrm{kg} \mathrm{IM}$ ) (Dormicum, F. Hoffmann-LA Roche Ltd, Switzerland), followed by induction with ketamine (40 mg/kg IM) (Ketamin 10\%CP-Pharma, Germany), intubation with an endotracheal tube (ID 3.0) for inhalatory isoflurane (Forane, Baxter, USA) anesthesia and life support monitoring (Mindray, Mec-1200 VET noninvasive multiparameter, China). For the orthopedic technique, standard materials were used. The buzzard was antiseptically prepared for the surgical intervention. The fractures were reduced using the retrograde internal pinning technique $(6,12)$, by using a threaded rod adapted to the length and width of the avian bone. Simple interrupted sutures were used to close up soft tissues with resorbable threads (Bicril 3/0, BioSintex, Romania).

Antibiotic spray (Terramycin spray, Pfizer, USA) and temporary figure-of-eight wing bandage was applied over the sutured lines. Analgesics $(4)$ and antibiotics $(5,14)$ were administrated post-op. Antibiotic therapy was started, with a $10 \mathrm{mg} / \mathrm{kg}$ of $5 \%$ enrofloxacin (Baytril 5, Bayer, Germany) solution diluted $1: 1$ with $0.9 \% \mathrm{NaCl}$ IM BID (B. Braun Pharmaceuticals SA, Romania), alongside $0.5 \mathrm{mg} / \mathrm{kg}$ of butorphanol (Butomidor 1, Richter Pharma, Austria) IM QID, to avoid infections and ease pain.

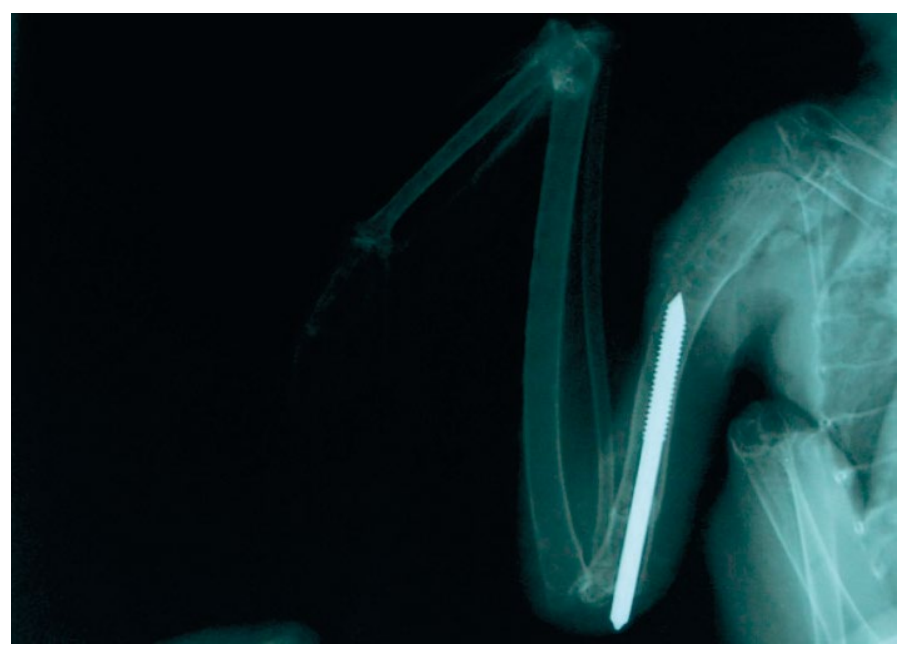

Fig. 3. X-ray exposure at 21 day post-op, showing humeral callus presence, indicating rapid bone healing 
The wing's biomechanics were assessed daily and wound treatment was performed on a daily basis. Initial assisted feeding was performed until the hawk was able to feed on its own and use the cage perch.

Postoperative X-rays were performed after 3 (Fig. 2) and 21 days (Fig. 3). X-rays showed that evolution was favorable; the humeral fracture callused completely, so the pin was removed after 21 days. The bird was moved in a bigger cage, and physiotherapy was continued for flight regaining capacity.

Case 2. The $2^{\text {nd }}$ Buteo buteo presented to the emergency hospital had a gun shot inflicted right wing fracture. After consultation, the bird of prey was diagnosed with proximal, opened-complex-radio-ulnar right wing fracture. In order to confirm and gather more details regarding the fracture site, after the X-ray exposure (Fig. 4), the bird was admitted. In this hawk, after following the same anesthetic, surgical, imagistic and post-op protocol, from the two fractured bones only the ulna was pinned.

At 21 days after surgery, because of mechanical support offered to the wing, it was decided not to remove the rod. At 30 days after initial consultation, despite callus presence on X-rays (Fig. 5), due to presence of osteomyelitis

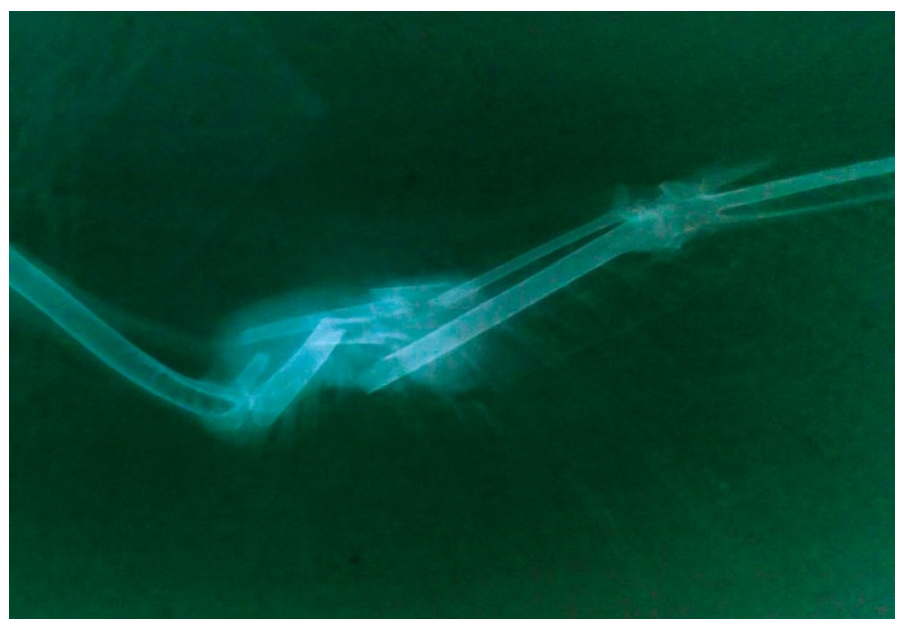

Fig. 4. Right wing X-ray showing a proximal, radio-ulnar, open, complex fracture with no contact between the main bone fragments

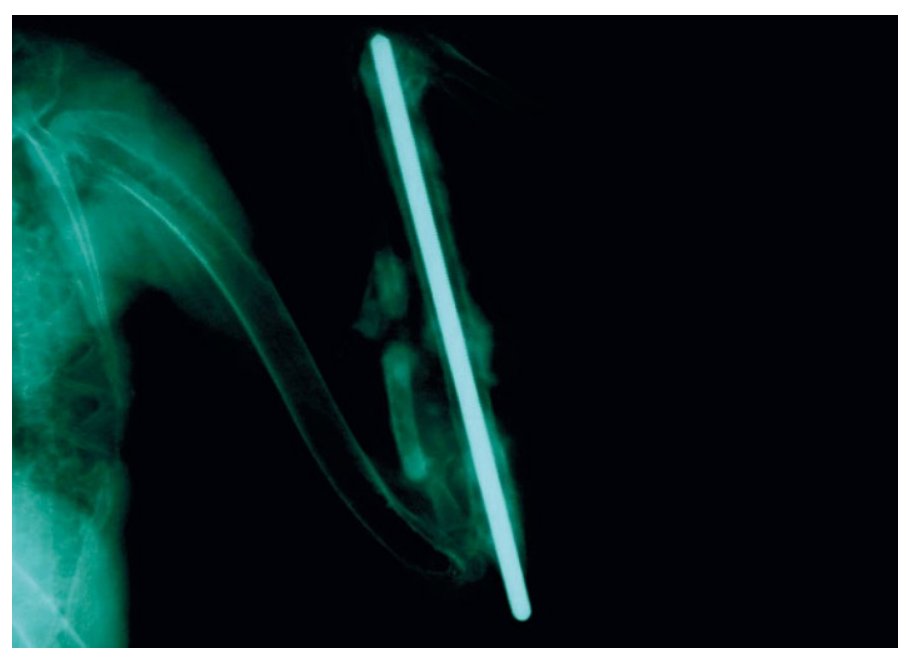

Fig. 5. X-ray image taken on day 21 post-op of the proximal, forearm fracture, showing periosteum, callus and healing activity, with presence of sequestrum

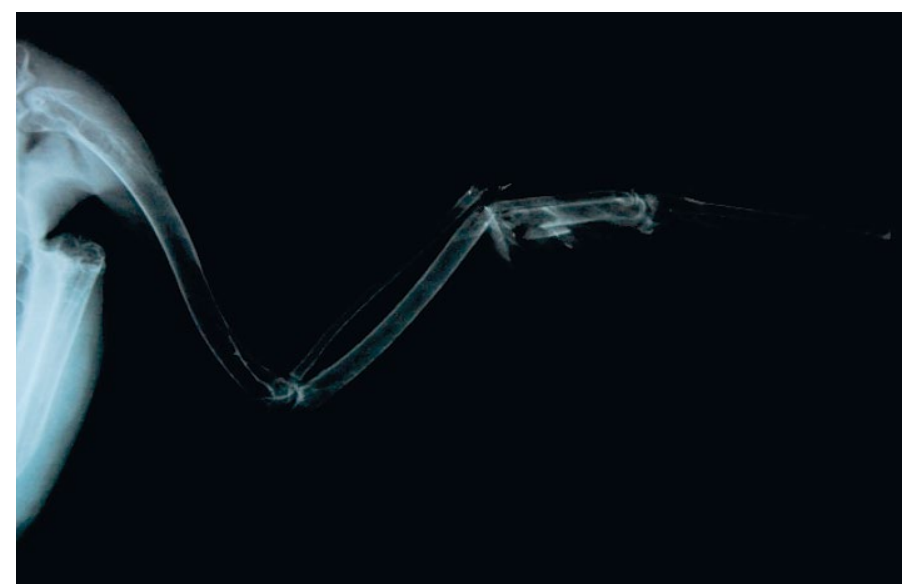

Fig. 6. Right wing X-ray, showing a distal, radio-ulnar, open, wedge fracture

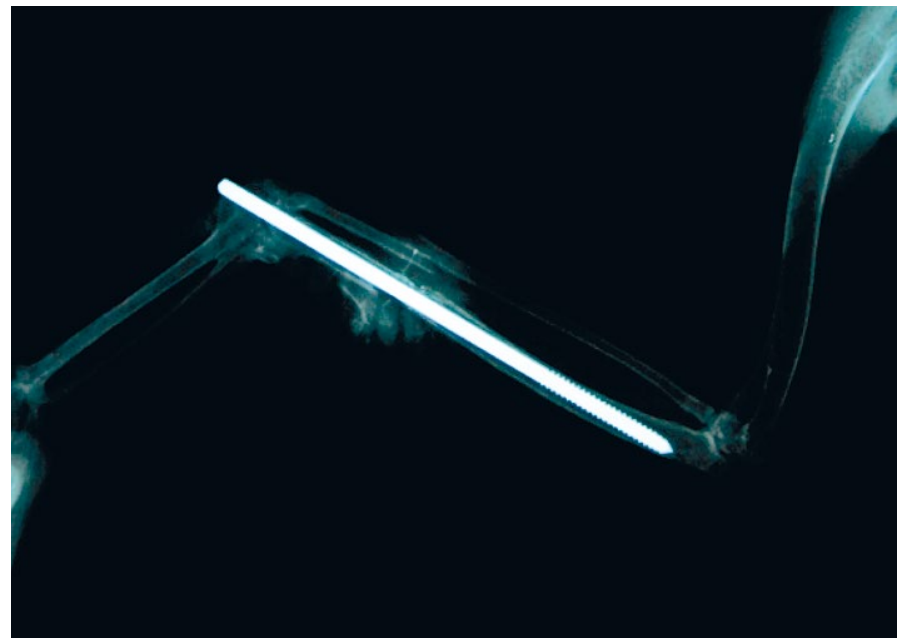

Fig. 7. X-ray image taken after 7 days in the distal forearm fracture, showing callus formation and periosteum activity

and excessive mobility of fracture site, the buzzard had to be euthanized.

Case 3. The $3^{\text {rd }}$ Buteo buteo patient that arrived at the emergency hospital, presented a distal, open-wedge-radioulnar right wing fracture, with additional sectioning of the radial nerve. The buzzard was admitted, and X-rays confirmed and provided additional data regarding the fractured area (Fig. 6).

In this bird, the same above-mentioned protocols were used, but because of fracture instability, an X-ray was performed on the $7^{\text {th }}$ day post-op. At 1 week after reduction of the fracture, callus presence was also noticed (Fig. 7), but at 10 days post-op, due to limb inertia, muscular atrophy and paresis, caused by the sectioning of the radial nerve, the bird was euthanized.

\section{Results and discussion}

The anesthetic protocol (4) used in this study, premedication with midazolam, induction with ketamine and maintenance on isoflurane, generated comfort during surgery for both the surgeon and the birds.

In general, in avian patients, forearm fractures are the most common types of fractures encountered (16). In such cases it is suggested (6) that the radius coaptation is mandatory, and the fixation of the ulna is optional. 
In contrast with this author's recommendation, in some older books (12) it is stated that the ulna should be reduced and pinned. However, other reports (15) recommend pining of both fractured bones in order to avoid synostosis formation. Moreover, considering the short healing time and the rigidity obtained, pinning of the ulna becomes the method of choice (6). The present research shows that retrograde internal pinning is effective as long as the technique is not accompanied by post-op complications such as osteomyelitis or radial nerve sectioning. In the first case, due to the lack of complications, the humeral pinning was successful.

The main disadvantages of internal fixators are wing paresis, injuries to the tendons, ligaments and blood vessels with delays in bone remodeling (12). These complications had also been noticed in the birds with forearm fractures that were admitted to the veterinary hospital.

The thickness of the pins should be no more than $2 / 3$ of the medullar canal circumference. Thicker pins block blood flow from the endosteal level resulting in avascular necrosis or iatrogenic fractures $(6,12)$. Thicker rods should be avoided in infected fractures as bacteria may be introduced in the intramedullary canal (17). However, intramedullary pins are easy to manage, therefore are frequently used, but in some cases they are ineffective despite being the best option. Their major disadvantage consists in failing to protect the fracture from rotational or shear forces (12).

In order to fix avian fractures, external skeletal fixators are generally considered to be more effective, but internal fixators produce less cortex damage and are easier to apply. It has been shown that for pneumatic bones threaded pins with negative profiles are more effective regarding the pin pull-out strength than smooth pins (11).

According to literature reports, birds with comminuted forelimb fractures tend to have a higher mortality rate (2). This observation may explain the complications that occurred in the two patients with forelimb fractures from the present case series.

Callus formation can be observed within 10 days post-op if bone alignment is perfect, and radiological assays may be performed at 7 (Fig. 7) and 21 days (Fig. 3, 5). At 21 days post-op the pin may be loosened if the callus formation processes are normal. Bone sequestra may be seen on X-rays during this period and it can be eliminated. Healing should be complete in 6 weeks and the pins can be removed (5).

Some authors (12) suggest that radiological examination should be performed at 2 to 4 week intervals to follow up on callus formation, also mentioning that healing-related changes may look like pathological findings, such as osteomyelitis, periosteum activity, sclerosis, and intramedullary high radiodensity.

Radiological examination could also be performed between 10 and 14 days to keep track of the healing processes, highlighting that healing occurs sometimes with fibrous tissue formation, which initially is not observable on radiological images, whilst palpation of the fractured sites brings additional precious data about fracture stability (6). In the present cases, at 3 (Fig. 2) and 21 days (Fig. 3, 5) post-op, X-rays showed a favorable evolution of the fractured ends. The humeral fracture had callused and after 3 weeks the rod was removed. In the $2^{\text {nd }}$ case, a callus was also present but at 3 weeks, the fracture site was still mobile. In the $3^{\text {rd }}$ case, before the hawk was euthanized, at 10 days post-op, due to the instable reduced fracture site and local paresis, only one image was obtained at day 7 (Fig. 7). Even in this case the X-ray showed presence of healing processes.

During prolonged immobilization of the wing, white muscle fibers, that use glycogen, unlike red fibers that use fat, are prone to atrophy (3). Excessive fibrosis in a damaged tissue is formed due to a low oxygen intake; therefore, it is indicated that after surgical intervention on the humerus or ulna, the wing should stay tied to the body for no more than 2-3 days (3). In all cases, a figure-of-eight wing bandage was applied, which was removed 3 days after surgery. This time period should be respected in order to prevent wing restraint that can lead to the contraction of the patagial fascia. This inconvenience may be overcome by rigid fastening of the fracture site and by passive physiotherapy, manual or ultrasound massage (3).

Literature shows that passive physiotherapy should begin on the $2^{\text {nd }}$ day after surgery, under anesthesia (for humeral fractures) or after 10 days (for other type of fractures), in 5 minutes sessions, two times weekly (5). For all three patients, from the second day after reanimation wing biomechanics were assessed daily, alongside assisted feeding and stimulation to use the cage perch, until the patients were able to feed and climb themselves. In the first case, after the humeral fracture had callused completely, the bird was moved in a bigger cage in order to be able to regain the flight capacity.

Plumage maintenance is also of great importance for regaining flight capacity. Therefore, the presence of a correspondent perch will keep the flight feathers from contact with the cage floor. For a better protection, the feathers should be rolled into a protective bandage (3).

Antibiotics, such as cephalosporins or enrofloxacin (are given for 5 days post-op for uncomplicated fractures), clindamycin or amoxicillin with clavulanic-acid is recommended to be used for open, comminuted, infected fractures with osteomyelitis. Methylmethacrylate with antibiotic impregnate strips can also be of help $(5,6,14)$.

Opioids (butorfanol 1-4 mg/kg IM or PO QID) or nonsteroidal anti-inflammatory drugs (meloxicam $0.2-0.5 \mathrm{mg} / \mathrm{kg}$ IM or PO BID; caprofen $2-4 \mathrm{mg} / \mathrm{kg}$ PO BID; ketoprofen $2 \mathrm{mg} / \mathrm{mg}$ IM BID-QID) can be used for analgesic support $(4,14)$. Though efforts were 
made to prevent complications and pain by administrating post-op diluted enrofloxacin with $0.9 \%$ saline and butorphanol, it was only possible to recuperate one patient.

The technique used in this study showed positive results regarding bone healing processes, despite the late arrival of the birds to the hospital, which lead to complications like osteomyelitis, lack of soft tissue, and paresis, which lead to the euthanasia of the last two patients.

Certainly the study may be improved by increasing the number of birds taken into observation, but because of reluctance and poor information of the public awareness regarding wildlife, this requirement is hard to accomplish. Moreover, public awareness regarding the presence of these birds in the wild, near human settlements, feeding only on small birds and mammals, should be stressed out.

Though it was tried in only 3 Buteo buteo patients, the orthopedic technique used (intramedullary retrograde pinning), has proven its effectiveness for avian humeral and ulnar fractures. The technique is easy to apply by favoring callus formation in the first week after the intervention.

\section{References}

1. Battaglia A., Ghidini S., Campanini G., Spaggiari R.: Heavy metal contamination in little owl (Athene noctua) and common buzzard (Buteo buteo) frm northern Italy. Ecotoxicol. Environ. Saf. 2005, 60, 61-66, https://doi.org/ 10.1016/j.ecoenv.2003.12.019.

2. Carneiro M., Sargo R.: Fractura del miembro anterior en el ratonero común (Buteo buteo): estudio retrospectivo de 38 casos [Forelimb fractures in common buzzards (Buteo buteo): retrospective study of 38 cases]. Rev. Complut. Ciencias Vet. 2009, 3, 335-339, https://doi.org/10.5209/RCCV.23599.

3. Coles B. H.: Surgery, [in:] Coles B. H. (ed): Essentials of Avian Medicine and Surgery. Blackwell Publishing Ltd, Oxford 2007, p. 142-182, https://doi.org/ 10.1002/9780470692349.ch2.

4. Doneley B.: Analgesia and Anaesthesia, [in:] Doneley B. (ed.): Avian Medicine and Surgery in Practice, Companion and Aviary Birds. Manson Publishing Ltd, London 2010a, p. 245-254, https://doi.org/10.1111/j.1751-0813.2011.00801.x.
5. Doneley B.: Surgery, [in:] Doneley B. (ed.): Avian Medicine and Surgery in Practice, Companion and Aviary Birds. Manson Publishing Ltd, London 2010b, p. 255-284, https://doi.org/10.1111/j.1751-0813.2011.00801.x.

6. Helmer P., Redig P.: Surgical Resolution of Orthopedic Disorders, [in:] Harisson J. G., Lightfoot T. (eds.): Clinical Avian Medicine. Spix Publishing, Palm Beach 2006, p. 1-13, https://doi.org/10.1016/S0920-1211(01)00327-8.

7. Holz H. P.: Coracoid fractures in wild birds: Repair and outcomes. Aust. Vet. J. 2003, 81, 469-471, https://doi.org/10.1111/j.1751-0813.2003.tb13362.x.

8. Jędrzejewski W., Szymura A., Jędrzejewska B.: Reproduction and food of the Buzzard Buteo buteo in relation to the abundance of rodents and birds in Białowieża National Park, Poland. Ethol. Ecol. Evol. 1994, 6, 179-190, https:/ doi.org/10.1080/08927014.1994.9522993.

9. Jones R., Redig P. T.: Autogenous Callus for Repair of a Humeral Cortical Defect in a Red-tailed Hawk (Buteo jamaicensis). J. Avian Med. Surg. 2001, 15, 302-309, https://doi.org/10.1647/1082-6742(2001)015[0302:acfroa]2.0.co;2

10. Jonsson L. (ed): Les Oiseaux d'Europe d'Afrique du Nord et du Moyen-Orient. $1^{\text {st. }}$ ed. Nathan, Paris 1994

11. López García M., Beceiro A. M. L., Juárez V. V., Guzón F. M., Cantalapiedra A. G.: Holding Power of Three Different Pin Designs in the Femur and Ulna of the Common Buzzard (Buteo buteo). J. Zoo Wildl. Med. 2011, 42, 552-557, https://doi.org/10.1638/2009-0194.1.

12. Martin H., Branson R. W.: Orthopedic surgical techniques, [in:] Branson W. R., Harrison J. G., Harrison R. L. (eds.): Avian Medicine: Principles and Application. Wingers Publishing, INC, Lake Worth 1994, p. 1137-1171.

13. Naccari C., Cristani M., Cimino F., Arcoraci T., Trombetta D.: Common buzzards (Buteo buteo) bio-indicators of heavy metals pollution in Sicily (Italy). Environ. Int. 2009, 35, 594-598, https://doi.org/10.1016/j.envint.2008.11.002.

14. Paul-Murphy J.: Pain Management, [in:] Harisson J. G., Lightfoot T. (eds.): Clinical Avian Medicine. Spix Publishing, Palm Beach. 2006, p. 1-7, https:// doi.org/10.1016/S0920-1211(01)00327-8

15. Redig P., Cruz L.: Trauma-related medical conditions, [in:] Samour J. (ed.): Avian Medicine. Mosby Elsevier 2007, p. 203-254, https://doi.org/10.1201/ b15175.

16. Santos G. G. C., Matuella G. A., Mara Coraiola A., Silva L. C. S., Lange R. R., Santin E.: Doenças de aves selvagens diagnosticadas na Universidade Federal do Paraná (2003-2007) [Diseases diagnosed in wild birds from the Federal University of Paraná (2003-2007)]. Pesqui. Vet. Bras. 2008, 28, 565-570, https://doi.org/10.1590/S0100-736X2008001100005.

17. Slatter D. (ed): Textbook Of Small Animal Surgery, Vol. 2, $2^{\text {nd }}$. ed. Saunders W. B. Company, Philadelphia 1993, p. 2362.

18. Yildiz D., Bozkurt Büyükçopur E. Ü., Gültiken M. E., Yildiz K.: The first report of Eucoleus dispar (Nematoda: Capillariidae) in the common buzzard (Buteo buteo) in Turkey. Turkish J. Vet. Anim. Sci. 2015, 39, 751-753, https://doi. org/10.3906/vet-1506-62.

Corresponding author: Cosmin Mureșan, Department of Surgery, University of Agricultural Science and Veterinary Medicine, Calea Mănăştur 3-5, 400372 Cluj-Napoca, Romania; e-mail: muresanscosmin@gmail.com 